\title{
ARTICLE
}

\section{Complete congenital stationary night blindness maps on Xp11.4 in a Sardinian family}

\author{
Carla Rozzo ${ }^{1}$, Maurizio Fossarello ${ }^{2}$, Grazia Galleri ${ }^{1}$, Maria Giuseppina Miano ${ }^{3}$, \\ Alfredo Ciccodicola ${ }^{3}$, Gabriella Sole ${ }^{4}$ and Mario Pirastu ${ }^{1}$ \\ ${ }^{1}$ Istituto di Genetica Molecolare, CNR, Alghero \\ ${ }^{2}$ Clinica Oculistica, Università degli Studi di Cagliari \\ ${ }^{3}$ Istituto Internazionale di Genetica e Biofisica, CNR, Napoli \\ ${ }^{4}$ Istituto per lo studio delle Talassemie e Anemie Mediterranee, CNR, Cagliari, Italy
}

\begin{abstract}
$\mathrm{X}$-linked congenital stationary night blindness (CSNBX) is a hereditary non-progressive retinal disorder, which can appear in two different clinical forms, complete and incomplete, associated with $C S N B 1$ and $C S N B 2$ loci on $\mathrm{Xp}$. We describe a Sardinian family with complete CSNBX and define better the limits of the CSNB1 genetic locus on Xp11.4 through linkage analysis. Haplotype analysis showed two key recombinants, which restrict the CSNB1 locus to a region of about $3 \mathrm{cM}$ limited by markers DSX1068 and DSX6810 respectively. The locus that we describe is included in the CSNB1 locus defined by previous reports referring to the same clinical form of the disease. These results, in addition to other recent mapping reports about families from different geographical areas, confirm the genetic homogeneity of $\mathrm{X}$-linked complete CSNB.
\end{abstract}

Keywords: congenital stationary night blindness; haplotype analysis; linkage analysis; mapping

\section{Introduction}

$\mathrm{X}$-linked congenital stationary night blindness (CSNBX) is a hereditary non-progressive retinal disorder. The disorder is characterised by normal fundus appearance, decreased visual acuity, myopia, loss of scotopic vision and a negative shaped electroretinogram (ERG). Some authors have suggested that complete and incomplete CSNB may be identical clinical entities, depending on the degree of rod function. However Miyake $e t a l^{1}$ point out that the defect in the rod visual pathway is different in the two forms of

Correspondence: Carla Rozzo, Istituto di Genetica Molecolare, CNR, Alghero, Casella Postale, 07040 Santa Maria La Palma (Sassari), Italy. Tel: 3979946713 ; Fax: 3979946714 ; E-mail: cr@igm.ss.cnr.it

Received 26 August 1998; revised 20 January 1999; accepted 21 January 1999
CSNB suggesting different clinical conditions. CSNBX clinical heterogeneity fits well with its recently observed genetic heterogeneity, which has been documented by several linkage studies on different families. $^{2-8}$ Moreover, the gene responsible for CSNBX incomplete form was recently cloned and mapped to the CSNB2 locus. ${ }^{9,10}$ Results of these studies are summarised in Figure 1.

Two $C S N B X$ loci, $C S N B 1$ and $C S N B 2$, were initially mapped on Xp chromosome, proximal to MAOA and MAOB respectively. ${ }^{2-5}$ A third $C S N B X$ locus, described by Bergen et $a l^{6}{ }^{6}$ was in close linkage with the $R P G R$ gene, which is localised on $\mathrm{Xp} 21.1$ and is responsible for some forms of $\mathrm{X}$-linked retinitis pigmentosa (XLRP). ${ }^{11}$ These authors suggested CSNBX as an allelic variant of retinitis pigmentosa type 3 (RP3). A novel locus for incomplete CSNBX was recently identified $(C S N B 4)$ in a $5 \mathrm{cM}$ region between 


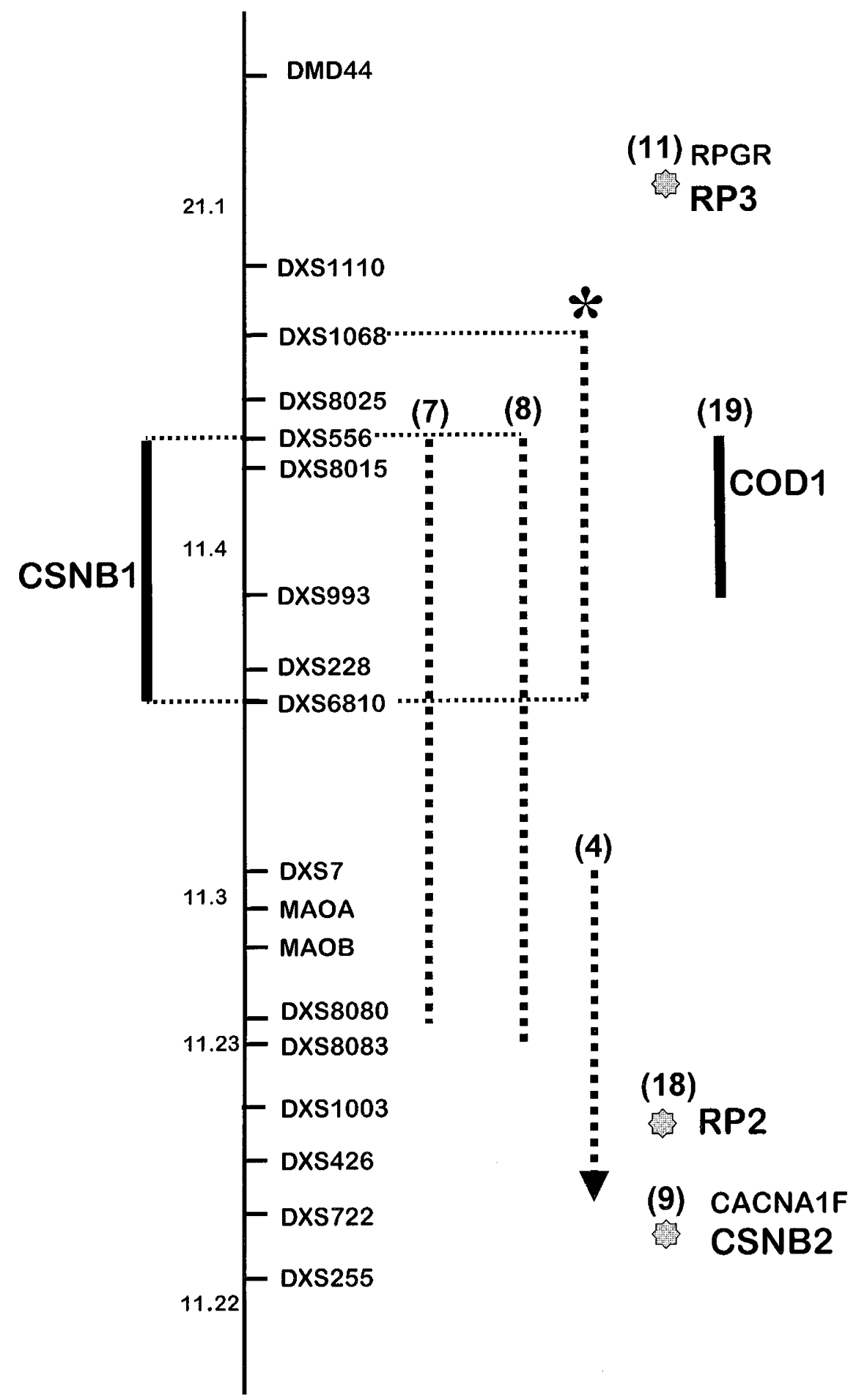

Figure 1 Mapping of CSNB1 locus on Xp11. An X chromosome portion is schematised in the diagram with polymorphic markers on the right. The black bar on the left represents the critical region containing the CSNB1 gene, resulting from different linkage studies. Broken bars represent CSNB1 locus mapping in different families and are numbered according to the text reference list. An asterisk marks our study's result. On the extreme right of the figure are represented COD1 locus, CSNB2, RP2 and RP3 genes, all mapped to that region. 
the retinitis pigmentosa loci $R P 2$ and $R P 3 .^{7}$ Boycott and collaborators recently gave a more precise location for the two loci CSNB1 and CSNB2, associated respectively with complete and incomplete forms of CSNBX. ${ }^{8}$ CSNB2 was finely mapped on $\mathrm{Xp} 11.23^{8}$ and the gene $C A C N A 1 F$, responsible for incomplete forms of CSNBX, was subsequently identified in this locus. ${ }^{9,10}$ CSNB1 was mapped on Xp11.4-p11.3 ${ }^{8}$ This interval includes the $C S N B 4$ locus, ${ }^{7}$ and partially overlaps with the $C S N B X$ locus associated with RP3, ${ }^{6}$ excluding, however, the RPGR gene.

In the present work we describe a Sardinian family with complete CSNBX. Linkage analysis allowed us to map the disease locus on $\mathrm{Xp} 11.4$ in a region that overlaps with the recently defined CSNB1 locus. Two key recombinants allowed us better to define the limits of this region. Moreover, our results confirm the genetic homogeneity of complete CSNBX.

\section{Methods}

\section{Clinical Studies}

We identified and examined a CSNBX Sardinian family. This family has been described in a preliminary report. ${ }^{12}$ Twentythree family members (Figure 2) participated in this study.

On the basis of a family history of long-standing night blindness and of clinical examination six males were found to be affected with CSNBX. All six patients had high myopia (12 diopters or more) with myopic astigmatism (2 diopters or more), nystagmus, low visual acuity (3/10 or less) and normal fundus, except for one case with tilted discs. Two out of six

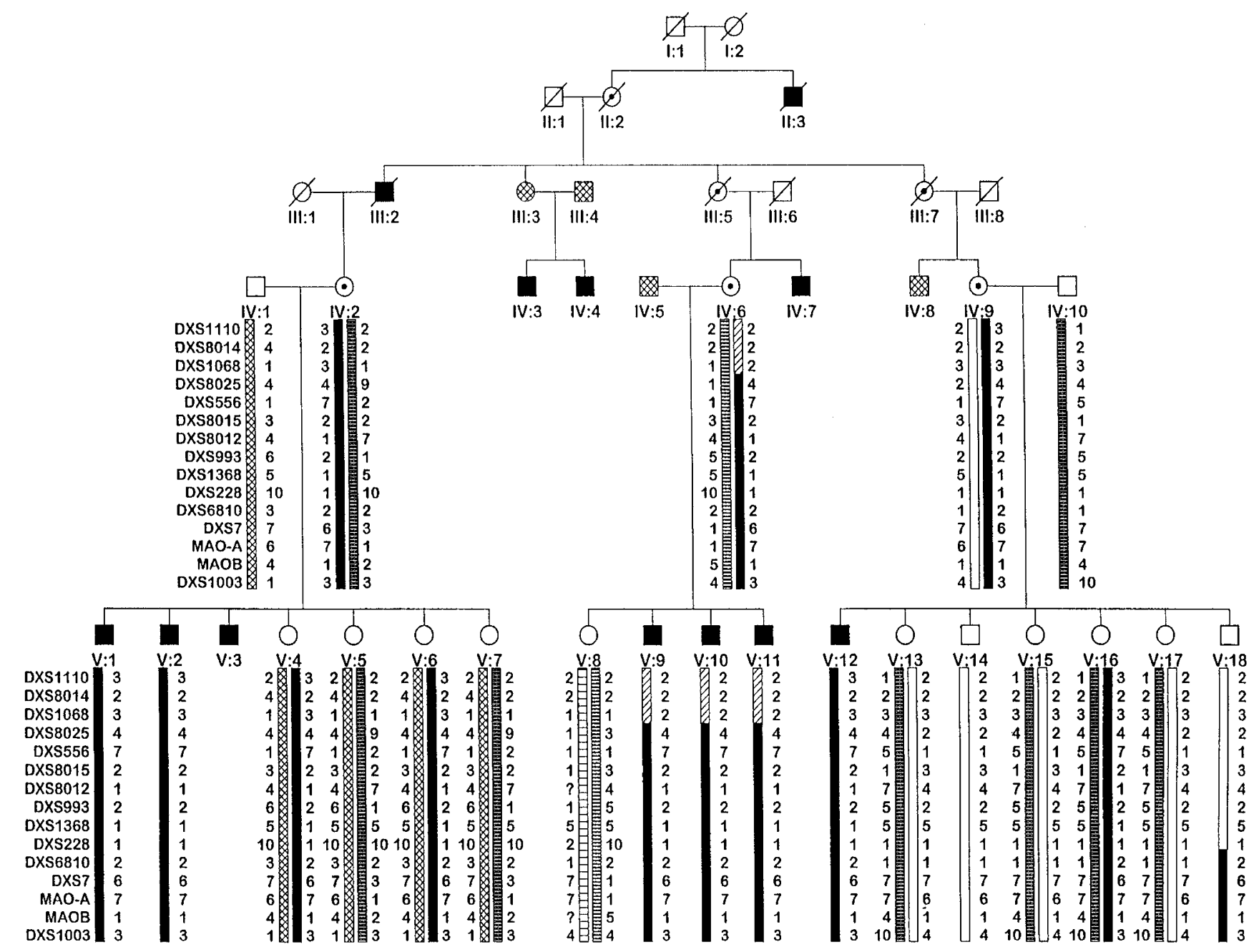

Figure 2 CSNBX Sardinian family. Markers used for linkage and haplotype analyses are listed to the left of the first individuals. Black symbols represent affected individuals, open symbols healthy individuals, dotted symbols healthy carrier females, and hatched symbols unexamined individuals. Black bars represent the disease-associated haplotype. The carrier female IV:6 shows a recombination defining the distal limit for the CSNBX associated region in this family, while the unaffected male V:18 shows a recombination defining the proximal limit. 
patients had surgically compensated juvenile glaucoma. Dark adaptation curves were monofunctional in all cases, with a normal cone adaptation curve. The electroretinogram showed complete form features, according to criteria established by Miyake et al. ${ }^{1,13,14}$ In accordance with the Declaration of Helsinki, informed constent was obtained and $10 \mathrm{ml}$ of venous blood were collected from each participating family member for genetic analysis.

\section{Genetic Analysis}

Genomic DNA was extracted from whole blood samples using standard 'salting out' procedure. ${ }^{15}$ To characterise the locus associated with the disease we performed microsatellite analysis using 15 polymorphic markers covering the cytogenetic regions Xp21.1-p11.4-p11.3. Several reports indicated this region to possibly contain one or more CSNBX genes. $^{2-5,7,8}$ The chosen markers were: tel DXS1110, DXS8014, DXS1068, DXS8025, DXS556, DXS8015, DXS8012, DXS993, DXS1368, DXS228, DXS6810, DXS7, MAO-A, MAO-B, DXS1003 cen (Figure 2). Microsatellite analyses were performed following standard procedures using specific primers deduced from Genome Database.

\section{Statistical Analysis}

Two-point linkage analysis was performed by the MLINK and ILINK routines of Fastlink package v.3.0P. ${ }^{16} \mathrm{~A}$ disease-allele frequency of 0.0001 and equal allele frequencies within each marker system were assumed. Penetrance values for carriers were set at 0.0000 . Support for linkage was evaluated by multilocus linkage analysis using the LINKMAP routine of Fastlink, with the following markers: DXS1110, DXS8025, DXS556, DXS8015, DXS8012, DXS6810, MAOB, and DXS1003. The reference genetic map used for the analysis were obtained from Généthon and Marshfield linkage map.

\section{Results}

Haplotype analysis detects a common haplotype among all the patients for markers DXS8025, DXS556, DXS8015, DXS8012, DXS993, DXS1368, DXS228 (Figure 2). The carrier female IV:6 shows a key recombination, which maps the disease locus proximal to marker DXS1068. The recombination has occurred in the maternal germline as demonstrated by subjects IV:2 and IV:9 carrying the original haplotype. A second key recombination is present in the unaffected male $\mathrm{V}: 18$, locating the $C S N B X$ locus distal to marker DXS6810 (Figure 2). This locus is therefore distinct from the $R P 3$ locus, which mapped distally to marker DXS1110, ${ }^{11}$ and from the RP2 locus, which mapped proximally to $\mathrm{MAOB}^{17,18}$ (Figure 1).

The highest two-point lod scores of 3.03 and 2.82 were obtained with DXS8025 and DXS556 respectively, at a recombination fraction of $\mathrm{q}=0.00$. Multipoint analysis was performed with the most informative linked markers to establish a 3-lod support interval: data suggest that the disease locus most likely lies in the interval DXS8025-0.2 cM (CSNB-DXS556)$1.5 \mathrm{cM}-\mathrm{DXS} 8015$ with a peak multipoint lod score of 3.56. However, the 3-lod support interval extends within the region between DXS8025 and DXS6810.

\section{Discussion}

The short arm of chromosome $\mathrm{X}$ is rich in genetic loci associated with retinal disorders. Many of these loci are overlapping and could represent allelic forms of the same gene..$^{2-8,11,18,19}$ However recently physical mapping and sequence analysis revealed a gene-rich area containing novel genes in the proximal portion of $\mathrm{Xp} .{ }^{20}$ Numerous and accurate genetic studies are necessary better to characterise the genetic differences among all the phenotypically heterogeneous eye diseases mapping to this region.

Mapping of $C S N B X$ genes on $\mathrm{Xp}$ was recently better defined. CSNBX incomplete form (CSNB2) was associated with mutations in the $C A C N A 1 F$ gene, a retinaspecific calcium channel $\alpha$-subunit gene, located in Xp11.23 between DXS722 and DXS255 markers. ${ }^{9,10}$ On the other hand, CSNBX complete form (CSNB1) was mapped on Xp11.4-p11.3. ${ }^{8}$

Our clinical and genetic results confirm the CSNB1 map described by Boycott and colleagues ${ }^{8}$ and restrict it to Xp11.4. Moreover, our data support the hypothesis that CSNB1 and CSNB2 represent different clinical entities. Our results, together with the recent CSNB1 mapping report, ${ }^{8}$ restrict the $C S N B 1$ locus to a region of about $2 \mathrm{cM}$, between markers DXS6810 and DXS556 (Figure 1).

Genetic homogeneity for complete CSNBX is supported by the fact that it maps on the same locus in several families of different geographical origin.

However, it is interesting to note that the locus CSNB4 associated with an incomplete form of the disease $^{7}$ maps to the same $\mathrm{Xp} 11.4$ region as the complete form CSNB1 (Figure 1). It is therefore possible that two different genes lie close to each other in this region, and they are responsible for complete and incomplete forms. Alternatively, a single gene could be responsible for both forms.

\section{Acknowledgements}

The authors thank all the patients and their families for their basic contribution to this work, Ms Silvia Cocchia for technical expertise, Dr Paola Melis for critical reviewing of the manuscript, Ms Giovanna Sechi and Giovanni LoVecchio 
for secretarial assistance. This work was supported by a grant from Assessorato alla Sanità, Regione Sardegna, and by Telethon, Italy.

\section{References}

1 Miyake Y, Horiguchi M, Terasaki H, Kondo M: Scotopic threshold response in complete and incomplete types of congenital stationary night blindness. Invest Ophthalmol Vis Sci 1994; 35: 3770-3775.

2 Aldred MA, Dry KL, Sharp DM et al: Linkage analysis in $\mathrm{X}$-linked congenital stationary night blindness. Genomics 1992; 14: 99-104.

3 Musarella MA, Weleber RG, Murphey WH et al: Assignment of the gene for complete X-linked congenital stationary night blindness (CSNB1) to Xp11.3. Genomics 1989; 5: 727-737.

4 Bech-Hansen NT, Moore BJ, Pearce WG: Mapping of locus for X-linked congenital stationary night blindness (CSNB1) proximal to DXS7. Genomics 1992; 12: 409-411.

5 Bergen AAB, Kestelin P, Leys M, Meire F: Identification of a key recombinant which assigns the incomplete congenital stationary night blindness gene proximal to MAOB. J Med Genet 1992; 31: 580-582.

6 Bergen AAB, Brink JB, Riemslag F, Schuurman EJM, Tijmes N: Localization of a novel X-linked congenital stationary night blindness locus: close linkage to the RP3 type retinitis pigmentosa. Hum Mol Genet 1995; 4: 931-935.

7 Hardcastle AJ, David-Gray ZK, Jay M, Bird AC, Bhattacharya SS: Localization of CSNBX (CSNB4) between retinitis pigmentosa loci RP2 and RP3 on proximal Xp. Invest Ophthalmol Vis Sci 1997; 38: 2750-2755.

8 Boycott KM, Pearce WG, Musarella MA et al: Evidence for genetic heterogeneity in X-linked congenital stationary night blindness. Am J Hum Genet 1998; 62: 865-875.

9 Bech-Hansen NT, Naylor MJ, Maybaum TA et al: Lossof-function mutation in a calcium-channel alpha1-subunit gene in Xp11.23 causes incomplete X-linked congenital stationary night blindness. Nat Genet 1998; 19: 264-267.
10 Strom TM, Nyakatura G, Apfelstedt-Sylla E et al: An L-type calcium channel gene mutated in incomplete $\mathrm{X}$-linked congenital stationary night blindness. Nat Genet 1998; 19: 260-263.

11 Meindl A, Dry K, Herrmann K et al: A gene (RPGR) with homology to the RCC1 guanine nucleotide exchange factor is mutated in X-linked retinitis pigmentosa (RP3). Nat Genet 1996; 13: 35-42.

12 Fossarello M, Pirastu M, Salgo MG et al: Use of recombinant DNA technology to map X-linked retinal dystrophies. In: Zingirian M, Cardillo Piccolino F (eds). Retinal Pigment Epithelium. Kugler \& Ghedini Publ: Amsterdam, Berkeley, Milan, 1989, pp 293-295.

13 Miyake Y, Yagasaki K, Horiguchi M, Kawase Y, Kanda T: Congenital stationary night blindness with negative electroretinogram: A new classification. Arch Ophthalmol 1986; 104: 1013-1020.

14 Miyake Y, Horiguchi M, Ota I, Shiroyama N: Characteristic ERG flicker anomaly in incomplete congenital stationary night blindness. Invest Opthalmol Vis Sci 1987; 28: $1816-1823$.

15 Grimberg J, Nawoschick S, Belluscio L, McKee R, Turck A, Eisenberg A: A simple and efficient non-organic procedure for the isolation of genomic DNA from blood. Nucleic Acid Res 1989; 17: 8390.

16 Cottingham RW Jr, Idury RM, Schaffer A: Faster sequential genetic linkage computations. Am J Hum Genet 1993; 53: 252-263.

17 Thiselton DL, Hampson RM, Nayudu M et al: Mapping the RP2 locus for $\mathrm{X}$-linked retinitis pigmentosa on proximal Xp: A genetically defined $5 \mathrm{cM}$ critical region and exclusion of candidate genes by physical mapping. Genome Res 1996; 6: 1093-1102.

18 Schwann U, Lenzner S, Dong J et al: Positional cloning of the gene for X-linked retinitis pigmentosa 2. Nat Genet 1998; 19: 327-332.

19 Seymour AB, Dash-Modi A, O'Connell JR et al: Linkage analysis of X-linked cone-rod dystrophy: location to Xp11.4 and definition of a locus distinct from RP2 and RP3. Am J Hum Genet 1998; 62: 122-129.

20 Fisher SE, Ciccodicola A, Tanaka K et al: Sequence-based exon prediction around synatophysin locus reveals a generich area containing novel genes in human proximal Xp. Genomics 1997; 45: 340-347. 